\title{
A Simple Model of Copyright Levies: Implications for Harmonization
}

\author{
Jin-Hyuk Kim*
}

\begin{abstract}
This paper analyzes optimal copyright levies in a representative consumer model and derives welfare implications for harmonization of levy rates. When the policymakers place enough weight on the interests of collecting societies, harmonization could lead to a reduction in social welfare. When countries are asymmetric, the country with a larger proportion of foreign consumption and more inefficient tax system loses more from harmonization. A calibration exercise using European data shows that harmonization would increase aggregate welfare. In some countries, both consumers and policymakers are better off; however, in others, policymakers are worse off although consumers would gain from harmonization. (JEL F42, O34, O52)
\end{abstract}

Keywords: copyright levies; international harmonization

${ }^{*}$ Department of Economics, University of Colorado at Boulder. E-mail: JinHyuk.Kim@Colorado.edu. 


\section{Introduction}

A copyright levy, also called as a private copying levy, is a special tax that is charged on various copying equipment and blank media that consumers use to produce copies for private use and for non-commercial purposes. The levy systems were introduced in many European countries under the EU Directive on the harmonisation of certain aspects of copyright and related rights in the information society $(2001 / 29 / \mathrm{EC}) .{ }^{1}$ However, there is no Europeanwide levy system, but each Member States sets different levy rates to the same recording equipment and media. In all instances, the levies are set and administered by copyright collecting societies acting on behalf of rights holders. ${ }^{2}$ This process has often prompted heated national debates over the appropriate level of levies.

On the other hand, national variation in the size of levies distorts the single market, and the European Commission has attempted to harmonize copyright levies. The initiative launched by Charlie McCreevy, the Internal Markets Commissioner for the EU, in 2006 to harmonize levies was, however, aborted after political pressure from France. Press reports say that McCreevy was forced to back down by Commission President, who was indirectly pressured by French collecting societies and by the French government allegedly because income from the levies is used to finance cultural events and projects (Mallinder 2008; Niemann 2010). Since then, the variation in levies remains considerable. For instance, in 2010

\footnotetext{
${ }^{1}$ The Directive, in particular Article 5.2(b), allows Member States to introduce a variety of private copying exceptions and to provide for fair compensation for rightholders for the use made of their protected works. 22 out of the 27 Member States have implemented the exception accompanied by a levy system. In Ireland and the UK, private copying exceptions other than the time-shifting of broadcasts are not authorised, whereas in Malta, Greece, and Luxembourg, private copying exceptions were legislated into a law but no levy system has been introduced or enforced.

${ }^{2}$ For instance, rightholders in foreign countries receive their dues via their local collecting society under the series of bilateral reciprocal agreements that each collecting society has with its sister societies in other countries.
} 
the levy on a $\mathrm{CD}$ varies from $€ 0.35$ in France to $€ 0.03$ in Switzerland.

Collecting societies seem to wield influence by lobbying at the national and supranational level. Levy rates have been increasing, and legislations to cut levies have been deterred. Levies are often considered as a source of revenue for collecting societies as well as for rightholders. In particular, collective societies, before distributing the collected levies to domestic or foreign rightholders, often deduct a part of the collections to fund a variety of social and cultural programs for national artists from music festivals to pension funds. The proportion of deductions are set by the national laws, which vary across countries. That is, cultural funds are a matter of national policy with little cross-border effects, so the deductions are set by each country's policymaker even if the levy were harmonized.

This paper builds a simple model to capture some of the salient features of copyright levy system. Based on the premise of the Directive that private copying causes economic harm to the rightholders, the model assumes that the levies can substitute in for the lower income that would result under private copying. Following Johnson (1985), the focus is on the long run, and I assume that the supply of creative goods would depend positively on the amount of creator's remuneration. In addition, the efficiency loss associated with commodity taxation is captured with an increasing function of levy rate, and the national policymakers are assumed to maximize the weighted sum of a representative consumer's utility and the size of cultural funds reflecting the collecting societies' influence on them.

The basic findings are intuitive. The levy rate chosen by the policymaker is always positive because of the market failure. Deduction for cultural funds is provided only when the policymaker places a sufficiently large weight on the interests of collecting societies. At the interior solution, the levy rate increases with the collecting society's influence and 
decreases with the marginal cost of taxation. An increase in consumer's marginal utility reduces the size of cultural funds, but the levy rate remains the same. This basic model is then extended to a two-country setting to investigate the effects of harmonization of levy rates across countries, where the two countries are linked through leakages and injections of levy collections that are distributed to foreign rightholders after deductions.

As is well known in the literature on macroeconomic policy coordination, harmonization of levies would internalize the spillovers across countries. This can be seen clearly in a symmetric country case, where the harmonized levy would be higher relative to the noncooperative level. However, under the influence of collecting societies, this means that the levy is even higher, so that both countries could be made worse off after harmonization. When countries are asymmetric, the country with a larger share of foreign consumption and more inefficiency from commodity taxation would see its levy increase due to harmonization, and thus would be made worse off. Therefore, in the real world, where countries are heterogeneous, the aggregate welfare effects could be ambiguous.

To assess how well the model explains the real world and what predictions it yields regarding the harmonization efforts, I calibrate the above model using available data on how the levies were distributed to domestic and foreign rights holders, respectively, and for the social and cultural purposes in ten European countries. The estimated policymaker's weight on the size of cultural funds is three times larger than the weight on a representative consumer, from which each countries' inefficiency parameter is backed out. The harmonized levy rate is calculated by maximizing the aggregate utility of the policymakers using both equal weight as well as the actual number of votes in the European Council. Given this, the size of cultural funds are determined by each policymaker. 
This exercise reveals that while the harmonization increases the aggregate social welfare, which is defined as the sum of each country's consumer welfare including any efficiency loss but excluding the policymaker's weight on cultural funds, there is a considerable variation across countries. For instance, Germany and Spain gain the most from the harmonization and their policymakers are also made better off with harmonized levies. However, in some countries, like France and Austria, the policymakers are made worse off and thus may oppose to harmonization initiatives despite that their consumer welfare would increase moderately. Another finding is that a fewer number of policymakers would be made worse off by the harmonization if the countries' voting rights were equally distributed.

The remainder of this paper is organized as follows. Section 2 briefly discusses the relevant literature. Section 3 lays out the basic model and characterizes the equilibrium. Section 4 extends the model to a two-country setting and analyzes the implications of harmonization both for symmetric and asymmetric countries. Section 5 calibrates the model using data from ten European countries and calculates the welfare consequences of counterfactual, harmonized levies. Section 6 concludes.

\section{Literature Review}

Economists have taken an interest in the copying and copyright issues with the advances of copying technologies. The two most thoroughly investigated issues appear to be the shortrun pricing effect and the optimal level of copyright protection. ${ }^{3}$ Recently, researchers have

\footnotetext{
${ }^{3}$ See, for example, Novos and Waldman (1984) and Liebowitz (1985). The literature has developed well beyond these seminal papers, which I do not attempt to survey here. See Peitz and Waelbroeck (2006) and Towse et al. (2008) for recent surveys.
} 
begun to examine the issue of hardware taxation or copyright levies. For instance, Chen and Png (2003) show that it is socially optimal to charge a levy on copying media rather than to impose a fine on infringing users. In Gayer and Shy (2003), the optimal levy rate is positive when piracy endangers the existence of creative industry which has a high fixed cost. Kinokuni (2005) adds that the optimal levy rate could be positive because if the levy is too low, then creators may adopt copy-protection technology.

The strength of this short-run framework is its micro-foundation of profit-maximizing behavior for a given copyrighted good, whereas long-run analysis that addresses the supply response has been generally lacking in these models. An important exception is Johnson (1985), who captures the supply response in the long run with a simple reduced form equation that is an increasing function of the profit. ${ }^{4}$ He then performs social welfare calculation based on his model and finds that the optimal levy can be a large fraction (68 percent) of the market price of the originals because the long-run benefit exceeds the short-run cost. This paper contributes to the long-run assessment of the copyright levy system that takes into account the influence of collecting societies on the policymakers. ${ }^{5}$

This paper is also related to the literature on international policy coordination. The traditional approach is to model interacting governments as optimizing agents who choose policy instruments. Not surprisingly, the basic finding is that, in models of international spillovers, coordination can lead to an efficiency gain. In some instances, however, policy

\footnotetext{
${ }^{4}$ Another strand of literature examines the supply response to changes in copyright terms, where recent empirical evidence suggests that the current copyright term may be excessive (see, e.g., Boldrin and Levine 2009; Png and Wang 2009).

${ }^{5}$ Huang and Png (2010) empirically find some evidence that levies are influenced by both content producers's lobbying and the median consumer's preference. More specifically, the odds of having a levy system are higher in countries where consumers' ethical costs are lower, which is consistent with lobbying equilibrium. However, when interacted with a measure of democracy, the odds are lower with lower ethical costs, which is an evidence that levies are also influenced by consumers' preferences.
} 
coordination can be counterproductive. ${ }^{6}$ In investigating incentives to harmonize intellectual property protection through international treaties, Scotchmer (2004) shows that harmonization can improve upon tendencies to underprovide unilateral protection due to outflow of profits, but it is not an efficient solution when unilateral protection is sufficient for incentives or public sponsorship is the most efficient way to fund R\&D.

This paper shows another channel through which policy coordination may reduce welfare. That is, when the policymaker maximizes his own objective function that weighs more heavily on lobbying group than social welfare, coordination which internalizes foreign spillovers could move government policy in the direction of reducing social welfare. When countries are asymmetric and policies are strategic substitutes, Casella (1992) shows that not all cooperative equilibria will dominate noncooperative solution, in particular, from the point of view of smaller or weaker countries. This general intuition holds in this paper, too. Moreover, calibration results seem consistent with Casella's argument that the weaker countries need more than proportional weight in common policy-making.

\section{The Model}

Consider a society, which is populated by a unit measure of identical consumers who have quasi-linear preferences on consumption of copyrighted goods and a numeraire. I assume that due to an easy access to copying technology and the prohibitive cost of monitoring

\footnotetext{
${ }^{6} \mathrm{~A}$ well-known case is that when policymakers face time-inconsistency problems, coordination eliminates competition between policymakers, who then become more opportunistic ex post and adopt a policy that reduces the representative citizen's welfare (Rogoff 1985).
} 
private copying, the measure of consumers who purchase the originals is zero in equilibrium. ${ }^{7}$ That is, market failure occurs and no copyrighted goods will be supplied without effective copyright protection because of its public good nature. Thus, the government has to tax the sale of copying equipment and/or blank media as a second-best solution. The government also determines how much to deduct from the levy collections for cultural funds.

These funds are spent on hosting various cultural and social events as well as supporting welfare programs for authors and artists. I assume that the number of authors and artists is finite, hence measure zero, so that the spent on cultural funds do not contribute to the social welfare, which in this model is the same as consumer welfare. This is a simplifying assumption, but on the other hand, the use of such deductions has not been well understood due to the closed nature of the collecting society's businesses. Moreover, recently, some collecting societies have been charged with fraudulently siphoning off funds destined for artists. Let $\tau$ and $\kappa$ denote the size of the levy and cultural deductions per consumer.

After deduction, levy proceeds are distributed to the rightholders as private copying remuneration, which stimulates the long-run supply. I assume a simple linear production technology, $l=\tau-\kappa$, where $l$ is the supply of creative goods. ${ }^{8}$ Assume that the consumer's utility function $u(l)$ satisfies the Inada conditions. The levies also create the usual deadweight loss associated with commodity taxation, which is captured by a continuous convex function $\Gamma(\tau)$, where $\Gamma^{\prime}(\tau)>0, \Gamma(0)=0$, and $\Gamma^{\prime}(0)=0$. The cultural funds as well as the levies are

\footnotetext{
${ }^{7}$ Note that it is due to the nature of representative consumer model that an individual chooses to copy rather than buy the original although he knows that all the other individuals would act in the same way. Assuming heterogeneous copying costs, which leads to a non-zero fraction of the consumers buying the original goods, does not have a substantive implication in this paper. Thus, I abtract from the issue of whether private copying levy is necessary at all.

${ }^{8}$ This is in fact not a crucial assumption because to satisfy the second-order condition, it suffices to assume that the consumer's utility, $u(l)$, is concave in $\tau$ and $\kappa$. That is, production technology may exhibit decreasing or moderately increasing returns to scale as long as utility from consumption is sufficiently concave.
} 
administered by collecting societies, and as monopoly entities in many European countries, they have been successful in influencing the policymakers through lobbying.

Following the literature on bureaucracy (e.g., Niskanen 1968), I assume that the collecting societies maximize their discretionary budget (i.e., cultural funds), $\kappa$. On the other hand, the policymaker's objective function can be drawn from the literature on lobbying. For instance, Grossman and Helpman (1994) focus on truthful equilibrium of a model in which the government policymaker maximizes a weighted sum of social welfare and campaign contributions and the lobbying group is willing to contribute up to the maximum benefit they derive from the policy. Thus, I assume that the policymaker maximizes a weighted sum of social welfare and the size of cultural funds, which collecting societies are willing to pay:

$$
\begin{gathered}
\max _{\tau, \kappa} u(\tau-\kappa)-\tau-\Gamma(\tau)+\delta \kappa \\
\text { s.t. } \tau \geq 0, \kappa \geq 0, \tau \geq \kappa,
\end{gathered}
$$

where $\delta<\infty$ is the weight attached to the interests of the collecting societies.

An interior solution $\left(\tau^{\circ}, \kappa^{\circ}\right)$ of the above maximization problem is characterized by the following two first-order conditions:

$$
\begin{aligned}
\delta & =1+\Gamma^{\prime}\left(\tau^{\circ}\right) \\
\delta & =u^{\prime}\left(\tau^{\circ}-\kappa^{\circ}\right) .
\end{aligned}
$$

From equation (2), it follows that the rate of copying levy, $\tau^{\circ}$, depends on the marginal costs of commodity taxation, $\Gamma^{\prime}(\tau)$, and the weight policymaker places on the size of cultural 
funds, $\delta$. However, the following proposition shows that if the weight placed on cultural funds is relatively low, then the policymaker does not provide any cultural funds $\left(\kappa^{\circ}=0\right)$ although the levy rate is always positive $\left(\tau^{\circ}>0\right)$. The intuitive reason for this is that unless $\delta$ is larger than the cost of raising public funds, the policymaker would rather reduce both the levy rate and cultural funds to benefit consumers than set aside any cultural funds. The following propositions characterize the policymaker's optimal choice $\left(\tau^{\circ}, \kappa^{\circ}\right)$ and show comparative statics results. All proofs are collected in the Appendix.

Proposition 1. There exists a value $\bar{\delta}>1$ such that the following characterizes domestic policy.

(i) For $\delta \leq \bar{\delta}, \tau^{\circ}>0$ and $\kappa^{\circ}=0$, where $u^{\prime}\left(\tau^{\circ}\right)=1+\Gamma^{\prime}\left(\tau^{\circ}\right)$ and $u^{\prime}\left(\tau^{\circ}\right)=\bar{\delta}$.

(ii) For $\delta>\bar{\delta}, \tau^{\circ}>0$ and $\tau^{\circ}>\kappa^{\circ}>0$, where $\delta=1+\Gamma^{\prime}\left(\tau^{\circ}\right)$ and $u^{\prime}\left(\tau^{\circ}-\kappa^{\circ}\right)=\delta$.

(iii) Both $\tau^{\circ}$ and $\kappa^{\circ}$ are continuous functions of $\delta$.

Proposition 2. Let $\bar{\delta}_{i}$ denote the threshold value when $\Gamma_{i}^{\prime}(\tau)$ and $u_{i}^{\prime}(\tau)$ are indexed by $i=A, B$.

(i) For $\delta \leq \bar{\delta}, \tau^{\circ}$ does not depend on $\delta$; for $\delta>\bar{\delta}$, both $\tau^{\circ}$ and $\kappa^{\circ}$ increase in $\delta$.

(ii) If $\Gamma_{A}^{\prime}(\tau)>\Gamma_{B}^{\prime}(\tau)$, then, $\tau_{A}^{\circ}<\tau_{B}^{\circ}$ for any $\delta ; \kappa_{A}^{\circ}<\kappa_{B}^{\circ}$ for $\delta>\bar{\delta}_{B}$, where $\bar{\delta}_{A}>\bar{\delta}_{B}$.

(iii) If $u_{A}^{\prime}(\tau)>u_{B}^{\prime}(\tau)$, then, $\tau_{A}^{\circ}>\tau_{B}^{\circ}$ for $\delta<\bar{\delta}_{A}$ and $\tau_{A}^{\circ}=\tau_{B}^{\circ}$ for $\delta \geq \bar{\delta}_{A} ; \kappa_{A}^{\circ}<\kappa_{B}^{\circ}$ for $\delta>\bar{\delta}_{B}$, where $\bar{\delta}_{A}>\bar{\delta}_{B}$.

Figure 1 depicts how the policymaker chooses the levy rate $\tau^{\circ}$ when $\delta \leq \bar{\delta}$ and $\delta>\bar{\delta}$, respectively. In Figure 1.(a), the policymaker equates the marginal cost of raising public 
funds, $1+\Gamma^{\prime}(\tau)$, with the marginal social benefit, $u^{\prime}\left(\tau^{\circ}\right)$. On the other hand, in Figure 1.(b), the policymaker equates the marginal social cost with his private marginal benefit from providing the cultural funds, $\delta$. That is, when $\delta$ is sufficiently high, social welfare is at a suboptimal level because the policymaker substitutes social marginal benefit with his private marginal benefit although there is no distortion on the cost of raising public funds, that is, $1+\Gamma^{\prime}(\tau)$.

This accords well with the findings in Proposition 2. For instance, in 2.(i), the effect of an increase in $\delta$ is to increase both $\tau^{\circ}$ and $\kappa^{\circ}$ when the policymaker places sufficient weight on cultural funds. In 2.(iii), an increase in the consumer's marginal utility does not lead to a higher rate of $\tau^{\circ}$ when $\delta$ is sufficiently high, although the policymaker responds by reducing the size of cultural deduction before distributing remuneration. On the other hand, 2.(ii) says that the policymaker always responds to an increase in the marginal cost of taxation by both decreasing the levy rate and, where applicable, reducing the size of cultural funds.

The implication for social welfare is straightforward. The policymaker's objective function coincides with social welfare when $\delta=0$. Proposition 1 says that the policymaker behaves as if he maximizes the social welfare as long as $\delta \leq \bar{\delta}$. That is, $\tau^{\circ}$ does not depend on $\delta$ and $\kappa^{\circ}=0$, which indeed maximize the social welfare. However, when $\delta$ is greater than $\bar{\delta}, \tau^{\circ}$ starts to exceed the socially optimal level, which creates an efficiency loss. Moreover, a positive $\kappa^{\circ}$ starts to get transferred to collecting societies, so it further decreases consumers' welfare. Therefore, an increase in $\delta$ beyond $\bar{\delta}$ causes social welfare to decrease. 


\section{Harmonization}

Consider two countries, $i=1,2$, each with a unit measure of identical consumers as specified in the previous Section. These two countries are linked together by the fact that some fraction, $0<\gamma_{i}<1$, of the consumption of creative goods in country $i$ are imports from country $j \neq i$. Hence, $\gamma_{i}$ of the levy collection in country $i$ flows out of country $i$ to the rightholders in country $j$. On the other hand, cultural funds are used to sponsor domestic programs only and hence are not transferred to the other country. In a noncooperative policysetting game, domestic policies $\left(\tau_{i}^{*}, \kappa_{i}^{*}\right)$ are chosen by the policymakers in each country $i$, who maximize the following objective function:

$$
\max _{\tau_{i}, \kappa_{i}} u\left(\left(1-\gamma_{i}\right) \tau_{i}-\kappa_{i}+\gamma_{j} \tau_{j}\right)-\tau_{i}-\Gamma\left(\tau_{i}\right)+\delta \kappa_{i}
$$

In the following, I assume an interior solution $\left(\tau_{i}^{*}>0, \kappa_{i}^{*}>0\right)$ for both countries. ${ }^{9}$ Then, the noncooperative solution is characterized by the following first-order conditions:

$$
\begin{aligned}
\left(1-\gamma_{i}\right) \delta & =1+\Gamma^{\prime}\left(\tau_{i}^{*}\right), i=1,2 \\
\delta & =u^{\prime}\left(\left(1-\gamma_{i}\right) \tau_{i}^{*}-\kappa_{i}^{*}+\gamma_{j} \tau_{j}\right), i=1,2, j \neq i
\end{aligned}
$$

From (5), it follows that $\tau_{i}^{*}<\tau^{\circ}$, where $\tau^{\circ}$ is the levy rate chosen in autarky. In a cooperative policy-setting context, on the other hand, the same levy rate, $\tau^{h}$, has to be chosen to maximize the sum of the two policymakers' objective functions. That is, the

\footnotetext{
${ }^{9}$ Considering the corner solution does not bring any technical innovation to the following analysis, but it only changes the strict welfare comparison to "at least as good as" statement.
} 
two countries have equal weight in a global policy-making body. ${ }^{10}$ However, it is assumed that the size of cultural funds are still set by the national policymakers. This is because, say, in Europe sponsoring cultural activities would have little Internal Market relevance. ${ }^{11}$ Note that since cultural activities do not have cross-border spillover effects, the policymakers choose $\left(\tau^{h}, \kappa_{1}^{h}, \kappa_{2}^{h}\right)$ simultaneously:

$$
\begin{gathered}
\max _{\tau, \kappa_{1}, \kappa_{2}} u\left(\left(1-\gamma_{1}\right) \tau-\kappa_{1}+\gamma_{2} \tau\right)-\tau-\Gamma(\tau)+\delta \kappa_{1} \\
\quad+u\left(\left(1-\gamma_{2}\right) \tau-\kappa_{2}+\gamma_{1} \tau\right)-\tau-\Gamma(\tau)+\delta \kappa_{2}
\end{gathered}
$$

It is straightforward to show that international policy coordination restores the levy rates to the level policymakers would have chosen without spillovers, that is, $\tau^{h}=\tau^{\circ}$.

The following result may seem counterintuitive, but it can be explained by the fact that policymakers tend to choose too high a levy rate when they place a sufficiently large weight on cultural funds. Levy rates are lower in the noncooperative regime than in the cooperative case because some fraction of levy collection flows out of the country. However, the previous Section establishes that a larger $\tau$ means a lower domestic welfare, holding other factors constant. By internalizing the externalities, policy coordination increases the levy rate, which reduces social welfare. Even if the corner solution is considered, harmonization cannot increase social welfare in the symmetric country case.

\footnotetext{
${ }^{10}$ The fact that the population as well as decision weight of the two countries are the same does not have substantive qualitative implications for the results that follow. Both assumptions will be relaxed in the next Section when the model is brought to the data.

${ }^{11}$ This is similar to the reason why "it would be hard to understand that the Commission would set a cap on, say, an obligation for certain types of companies to dedicate part of their profits to R\&D that was established by a Member State's legislation" (European Grouping of Societies of Authors and Composers 2008).
} 
The level of social welfare in the noncooperative and cooperative equilibria is defined as $S W_{i}^{*}=u_{i}\left(\left(1-\gamma_{i}\right) \tau_{i}^{*}-\kappa_{i}^{*}+\gamma_{j} \tau_{j}^{*}\right)-\tau_{i}^{*}-\Gamma_{i}\left(\tau_{i}^{*}\right)$ and $S W_{i}^{h}=u_{i}\left(\left(1-\gamma_{i}\right) \tau^{h}-\kappa_{i}^{h}+\gamma_{j} \tau^{h}\right)-\tau^{h}-\Gamma_{i}\left(\tau^{h}\right)$ for $i=1,2$, and let $\Delta S W_{i}=S W_{i}^{h}-S W_{i}^{*}$ denote the welfare change in country $i$ from harmonization.

Proposition 3. Let $S W_{i}$ denote the level of social welfare in country $i$ when $\gamma_{i}$ is indexed by $i$.

(i) If the two countries are identical in all respects, then $\Delta S W_{1}=\Delta S W_{2}<0$.

(ii) If the two countries are identical except $\gamma_{1}>\gamma_{2}$, then $\Delta S W_{1}<\Delta S W_{2}<0$.

Proposition 3.(ii) says that, when countries are asymmetric in terms of foreign dependence, both countries are still worse off under harmonized levy system; however, the country with less foreign dependence $(i=2)$ suffers less than the other country $(i=1)$ does. The reason is as follows. Since $\tau_{i}^{*}$ is determined by equation (5), $\gamma_{1}>\gamma_{2}>0$ implies $\tau_{1}^{*}<\tau_{2}^{*}<\tau^{h}$, which means that to harmonize the levy rate, country 1 has to increase the levy rate more than country 2 has to. Thus, the social welfare loss, defined as the area below the social marginal cost of raising additional public funds, $1+\Gamma^{\prime}(\tau)$, is larger in country 1 than in country 2. This area is illustrated in Figure 2.

One might wonder why the size of remuneration distribution net of cultural deduction does not change after harmonization of levy rates. The intuitive reason is that when the policymaker sets the domestic policy $\kappa_{i}$, he will transfer funds to collecting societies until consumers' marginal utility equals the policymaker's private marginal benefit, $\delta$. This means that any level change in domestic levy rate as well as net inflow (or outflow) of levy collections 
between countries are completely absorbed by changes in cultural funds. Therefore, as long as consumers' utility functions are the same across countries, there is no secondary effect on consumer surplus through adjustments in $\kappa_{i}$.

The next result considers two different types of asymmetry between countries. Proposition 4.(i) says that when the marginal social cost of raising public fund is smaller in country 2 than in country 1 , all other things equal, country 2 is better off than country 1 under harmonized levy system, both in absolute and relative terms. That is, country 2 either suffers less from increased levy or in fact gains from reduced levy rate. The intuition here is that absent any international spillover, the harmonized levy rate is determined by the average of the two social marginal cost functions, which means $\tau_{1}^{*}<\tau^{h}<\tau_{2}^{*}$. This force holds even in the presence of payment externality, hence the result.

Proposition 4. Let $S W_{i}$ denote the level of social welfare in country $i$ when $\Gamma_{i}^{\prime}(\tau)$ and $u_{i}^{\prime}(\tau)$ are indexed by $i$.

(i) If the two countries are identical except $\Gamma_{1}^{\prime}(\tau)>\Gamma_{2}^{\prime}(\tau)$, then $\Delta S W_{1}<0$ and $\Delta S W_{1}<$ $\triangle S W_{2}$.

(ii) If the two countries are identical except $u_{1}^{\prime}(\tau) \neq u_{2}^{\prime}(\tau)$, then $\Delta S W_{1}=\Delta S W_{2}<0$.

Proposition 4.(ii) adds that there are no welfare implications with regard to the shape of consumers' utility function. The logic is similar to the above. That is, because the domestic policymaker can completely undo the effects of harmonization on consumer surplus by adjusting the size of cultural funds, the net remuneration to domestic rightholders after any deductions and additions remains the same yielding the same amount of surplus. The 
results in Proposition 4.(i) and 4.(ii) are illustrated in Figures 3 and 4, respectively. The above Propositions imply that welfare implications of harmonization could be quite complex when the two countries differ in more than one respect.

\section{Calibration Exercise}

In this Section, I estimate the welfare consequences of harmonized levy system by fitting real world data to the model and calculating counterfactual, harmonized levy rate for ten European countries. This exercise is intended to only illustrate how the model can be applied to actual data; hence, caution needs to be exercised when interpreting the results of this exercise. Here the key identifying assumption is that the levy rates, $\tau_{i}$, are mainly determined by variations in foreign dependence and the cost of raising public funds across countries. This means that I hold constant the policymakers' weight on cultural funds and the consumers' utility function across countries. ${ }^{12}$

The dataset comprises all European countries for which the following data is available: levy rate on CD-R, size of cultural deduction, share of foreign distribution after deduction (see Table 1). Due to paucity of data, only 10 countries satisfy this requirement, and especially I was able to obtain the data on cultural deduction and foreign share of each country only for 2004. ${ }^{13}$ Annual data on copyright levies are made available by the Dutch Private Copying

\footnotetext{
${ }^{12}$ The first part of this assumption may be justified by the fact that there are lobbying activities at both national and supranational level, such as in the European Union or World Intellectual Property Organization, by national collecting societies and their umbrella organization. The second part of the assumption is simplifying.

${ }^{13}$ The original data is provided by European Grouping of Societies of Authors and Composers (GESAC), which represents 34 of the main collective copyright management societies in the European Union, Norway, and Switzerland, and the table is contained in the European Commission's First Call for Comments, "Copyright Levies in a Converging World" in 2006.
} 
Society through international surveys. ${ }^{14}$ Levy rates as well as populations are based on 2005 data. These do not vary substantially across years, so the following results should not be very sensitive to the particular year chosen here.

The overview of the calibration strategy is as follows. I first assume two functional forms to estimate a structural model: $u(l)=\ln l$ and $\Gamma_{i}\left(\tau_{i}\right)=\frac{\theta_{i}}{2} \tau_{i}^{2}$. From the first-order conditions, this yields $\tau_{i}^{*}$ as a function of $\gamma_{i}, \theta_{i}$, and $\delta$. I also derive a regression equation (which will follow shortly) that relates $\tau_{i}^{*}$ to $\kappa_{i}^{*}$. From the regression of this equation, parameter $\delta$ is identified and estimated (which is roughly 3 ). Using the estimated value of $\delta$, parameter $\theta_{i}$ can be recovered from the expression for $\tau_{i}^{*}$. With these estimated values, I calculate counterfactual, harmonized levy rate $\tau^{h}$ and the size of cultural funds $\kappa_{i}^{h}$ as predicted by the model in the previous Section. Social welfare is then evaluated at $\left(\tau_{i}^{*}, \kappa_{i}^{*}\right)$ and $\left(\tau^{h}, \kappa_{i}^{h}\right)$ together with those estimated parameter values, which allows welfare comparison between the two cases.

In the noncooperative setting, the policymakers' objective function is as follows:

$$
\max _{\tau_{i}, \kappa_{i}} \ln \left(\left(1-\gamma_{i}\right) \frac{\tau_{i}}{\alpha}-\kappa_{i}+\Omega_{j}\right)-\frac{\tau_{i}}{\alpha}-\frac{\theta_{i}}{2}\left(\frac{\tau_{i}}{\alpha}\right)^{2},
$$

where $\Omega_{j}=\left(\sum_{j \neq i} \gamma_{j} \tau_{j} \rho_{j}\right) / \rho_{i}$ represents the inflow of foreign levy collections to domestic rightholders adjusted by the total population $\left(\rho_{i}\right)$ in each country $i$ and $j$. Additionally, $\alpha$ is a scale factor which means that the average consumer consumes $\frac{1}{\alpha}$ unit of blank CDs in a year, and $\kappa_{i}$ is the size of cultural funds divided by the population. Assuming an interior

\footnotetext{
${ }^{14}$ See Png and Wang (2009) for an analysis using this panel data. The reason why other types of copyright levies (e.g., on MP3 players) are not used in the following analysis is that, first, those levy rates vary widely with the specifications of the devices; second, the levies are modelled in this paper as marginal costs rather than a fixed cost, so levy on blank CD is more suitable for this analysis.
} 
solution, the two first-order conditions are

$$
\begin{aligned}
& \frac{\frac{1-\gamma_{i}}{\alpha}}{\frac{1-\gamma_{i}}{\alpha} \tau_{i}-\kappa_{i}+\Omega_{j}}=\frac{1}{\alpha}+\frac{\theta_{i} \tau_{i}}{\alpha^{2}}, \\
& \frac{1}{\frac{1-\gamma_{i}}{\alpha} \tau_{i}-\kappa_{i}+\Omega_{j}}=\delta .
\end{aligned}
$$

Rearranging (10) yields

$$
\left(1-\gamma_{i}\right) \tau_{i}=\frac{\alpha}{\delta}+\alpha \kappa_{i}-\alpha \Omega_{j}
$$

The foreign inflow, $\Omega_{j}$, is not observed in the dataset, but the term $\alpha \Omega_{j}$ might be quite small. This is because most of foreign consumption in European countries are due to rights holders in the USA or UK (which are not in the dataset) rather than from each other. Given the cultural differences between the sample countries, this may be a plausible assumption. Moreover, there is an offsetting effect. Because collecting societies deduct a small portion of levy collections as administration fees, $\kappa_{i}$ could underestimate the size of all deductions prior to redistribution. If one believes that either these two forces roughly offset each other or there are other enough random factors, then I can specify the regression equation as follows:

$$
\left(1-\gamma_{i}\right) \tau_{i}=\frac{\alpha}{\delta}+\alpha \kappa_{i}+\varepsilon_{i}
$$

the estimate of which yields,

$$
\begin{array}{r}
\left(1-\gamma_{i}\right) \tau_{i}=.1074+.3189 \kappa_{i}, \\
(.028)^{* * *}(.162)^{*}
\end{array}
$$

where robust standard errors are in the parentheses and the coefficients are significant at 
the 1- and 10-percent level, respectively. By taking the ratio of the two coefficient, the point estimate of parameter $\delta$ is $\frac{.3189}{.1074} \simeq 2.9693$.

Combining (9) and (10) yields

$$
\tau_{i}=\frac{\alpha\left(\left(1-\gamma_{i}\right) \delta-1\right)}{\theta_{i}}
$$

Since $\tau_{i}, \gamma_{i}, \delta$, and $\alpha$ estimates are known, $\theta_{i}$ can be calculated for each country $i$.

In the cooperative setting, the policymakers maximize a weighted sum of each policymakers' utility function multiplied by the decision weight, $w_{i}$, attached to each country $i=1, \ldots, n$. Again, ignoring the $\Omega_{j}$ term, it is straightforward to show that the following two first-order conditions hold:

$$
\begin{aligned}
\sum_{i} w_{i}\left(\frac{\frac{1-\gamma_{i}}{\alpha}}{\left(1-\gamma_{i}\right) \frac{\tau^{h}}{\alpha}-\kappa_{i}^{h}}-\frac{1}{\alpha}-\frac{\theta_{i} \tau}{\alpha^{2}}\right) & =0 \\
\frac{1}{\left(1-\gamma_{i}\right) \frac{\tau^{h}}{\alpha}-\kappa_{i}^{h}} & =\delta .
\end{aligned}
$$

Using (14) and (15), harmonized levy rate and the size of cultural funds can be calculated as follows.

$$
\begin{aligned}
\tau^{h} & =\frac{\delta \sum_{i} s_{i}\left(1-\gamma_{i}\right)-1}{\frac{1}{\alpha} \sum_{i} s_{i} \theta_{i}} \\
\kappa_{i}^{h} & =\max \left\{\left(1-\gamma_{i}\right) \frac{\tau^{h}}{\alpha}-\frac{1}{\delta}, 0\right\}
\end{aligned}
$$

where $s_{i}=w_{i} / \sum_{i} w_{i}$ is the country $i$ 's share of the decision rights.

In the first scenario, countries have equal decision power, $s_{i}=\frac{1}{n}$, in setting the har- 
monized levy rate. The first two columns in Table 2 show the counterfactual, harmonized levy rate and each countries' (per capita) size of cultural funds implied by the model. The harmonized levy rate is around $€ 0.12$ per $\mathrm{CD}$, and the model also predicts that in most countries (except in the case of Latvia) cultural funds will not be provided under harmonized levy system. The next two columns compare the individual social welfare evaluated at $\left(\tau_{i}^{*}, \kappa_{i}^{*}\right)$ and $\left(\tau^{h}, \kappa_{i}^{h}\right)$. The signs of $\Delta S W_{i}=S W_{i}^{h}-S W_{i}^{*}$ indicate that in seven out of the ten countries, social welfare increases at the national level, whereas it decreases in the other three countries.

On the other hand, the last three columns calculate and compare the national policymakers' private utility before and after the harmonization. The policymaker's utility is denoted as $D M_{i}$, and it includes an additional term, $\delta \kappa_{i}$, to account for the collecting societies' influence. The signs of $\Delta D M_{i}=D M_{i}^{h}-D M_{i}^{*}$ indicate that five out of the ten countries' policymakers stand to lose from the harmonization. In particular, there are conflicts of interests in the sense that in Austria, Denmark, and France, policymakers would lose whereas consumers gain under harmonized levy system. This is mainly because in most countries, the levy rate will fall after harmonization and policymakers can no longer support for cultural funds.

In the second scenario, countries have unequal decision power. Specifically, I use the number of each countries' votes in the European Council to calculate their decision power, $s_{i}$. The results of the same exercise are presented in Table 3 . Here the model predicts that the harmonized levy rate will be even lower, at around $€ 0.09$ per $C D$, and no country will be able to sponsor cultural funds from the levy collection. In five out of the ten countries, social welfare increases, and only three countries' policymakers will support for the reform. 
Again, in Austria and France, policymakers stand to lose despite the gains to be achieved in terms of social welfare. This seems consistent with the anecdotal evidence discussed earlier.

Table 4 summarizes the welfare implications under these two scenarios. Changes in the individual social welfare are multiplied by the population size of each country, and these are added up to calculate the changes in the aggregate social welfare across the ten countries. Note, however, changes in the policymakers' utilities are added up without weighting. First, with equal decision power, this calibration exercise shows that aggregate social welfare increases as well as the aggregate measure of the policymakers' utilities. Therefore, with appropriate side transfers among the policymakers, the ten countries should be able to harmonize the levy rate. In doing so, countries like Spain, Germany, and France would benefit the most.

On the other hand, with unequal decision power, the model predicts that the aggregate social welfare still increases but to a lesser degree than before. Importantly, the change in the aggregate measure of the policymakers' utilities are now negative, meaning that even with side transfers the policymakers would not be able to agree among themselves on the reform proposal. This may explain why the efforts to harmonize the levy rate by the European Commission failed to succeed. In terms of aggregate social welfare, Germany and Spain would gain the most, but policymakers in other countries would lose. In particular, French policymaker would lose the most despite the moderate, predicted increase in the social welfare. 


\section{Conclusion}

Private copying exception and levy compensation for all its practical purposes have taken on growing importance in the digital age. For instance, Canada began collecting levies in 2000, where the levy can be as high as 90 percent of CD prices and millions of dollars have been distributed to rights holders, and other countries are considering levy systems. One of the controversies, however, regarding the levy system is that the levies vary significantly across countries. Notwithstanding international treaties to harmonize intellectual property rights, this phenomenon remains a puzzle. To my knowledge, this paper is the first to develop a tractable model and quantify the benefits and losses from harmonization of copyright levies.

The theoretical model is based on a familiar public good provision model with crossborder spillovers and in particular allows the policymaker's utility to depend on his concern for cultural funds (or, alternatively, transfers from collecting societies). Analysis of the model finds that the levy rate could be too high from social welfare perspective when the policymaker places enough weight on cultural funds. Because international policy coordination internalizes cross-border externalities, the basic force under harmonization is to increase the levy rate, and this can reduce social welfare. However, when countries are asymmetric, this becomes much more complex due to interactions between various components of the model.

Calibration of a version of the model yields predictions that seem to be consistent with how the European Commission's initiative to harmonize the levies failed due to disagreement from some Member States. That is, aggregate social welfare would increase, but some policymakers are made worse off because they can no longer sponsor cultural funds for collecting societies. Another finding is that the policymakers collectively do better when the 
decision weights are equally distributed, so the reform can be adopted with side transfers. While these results seem to accord well with some facts, this study is by no means exhaustive, and other issues should be taken into account when drawing policy conclusions regarding the levy systems.

\section{References}

[1] Boldrin, Michele, and David Levine (2009). "Market Size and Intellectual Property Protection." International Economic Review 50(3): 855-881.

[2] Casella, Alessandra (1992). "Participation in a Currency Union." American Economic Review 82(4): 847-863.

[3] Chen, Yeh-Ning, and Ivan Png (2003). "Information Goods Pricing and Copyright Enforcement: Welfare Analysis." Information Systems Research 14(1): 107-123.

[4] European Grouping of Societies of Authors and Composers (2008). Response to the Second Call for Comments, "Fair Compensation for Acts of Private Copying."

[5] Gayer, Amit, and Oz Shy (2003). "Copyright Protection and Hardware Taxation." Information Economics and Policy 15: 467-483.

[6] Grossman, Gene, and Elhanan Helpman (1994). "Protection for Sale." American Economic Review 84(4): 833-850. 
[7] Huang, Ke-Wei, and Ivan Png (2010). "Who Makes the Law? Political Economy Analysis and Evidence from Copyright Levies." Working Paper, National University of Singapore.

[8] Johnson, William (1985). "The Economics of Copying." Journal of Political Economy 93(1): 158-174.

[9] Kinokuni, Hiroshi (2005). "Compensation for Copying and Bargaining." Information Economics and Policy 17: 349-364.

[10] Liebowitz, Stan (1985). "Copying and Indirect Appropriability: Photocopying of Journals." Journal of Political Economy 93(5): 945-957.

[11] Mallinder, Lorraine (2008). "Electronics Industry to Continue Subsidies of Artists." European Voice, 21 February 2008. (Web. 13 March 2011.)

[12] Niemann, Fabian (2010). "The Online Market: Breaking the Copyright Levies Deadlock." Ericsson Business Review, 30 April 2010 (Web. 13 March 2011.)

[13] Niskanen, William (1968). "The Peculiar Economics of Bureaucracy." American Economic Review 58(2): 293-305.

[14] Novos, Ian, and Michael Waldman (1984). "The Effects of Increased Copyright Protection: An Analytic Approach." Journal of Political Economy 92(2): 236-246.

[15] Peitz, Martin, and Patrick Waelbroeck (2006). "Piracy of Digital Products: A Critical Review of the Theoretical Literature." Information Economics and Policy 18(4): 449476. 
[16] Png, Ivan, and Qiu-hongWang (2009). "Copyright Law and the Supply of Creative Work: Evidence from the Movies." Working Paper, National University of Singapore.

[17] Rogoff, Kenneth (1985). "Can International Monetary Policy Cooperation Be Counterproductive?" Journal of International Economics 18(3-4): 199-217.

[18] Scotchmer, Suzanne (2004). "The Political Economy of Intellectual Property Treaties." Journal of Law, Economics, and Organization 20(2): 415-437.

[19] Towse, Ruth, Christian Handke, and Paul Stepan (2008). "The Economics of Copyright Law: A Stocktake of the Literature." Review of Economic Research on Copyright Issues 5(1): $1-22$.

\section{Appendix}

Proof of Proposition 1. It is straightforward to check that the columns of the Jacobian of the constraints are independent, and thus the constraint qualification condition holds at any solution candidate. Form a Lagrangian and derive the full set of first-order conditions as follows:

$$
\begin{gathered}
L\left(\tau, \kappa, \lambda_{1}, \lambda_{2}, \lambda_{3}\right)=u(\tau-\kappa)-\tau-\Gamma(\tau)+\delta \kappa+\lambda_{1}(\tau-\kappa)+\lambda_{2}(\tau)+\lambda_{3}(\kappa), \\
u^{\prime}(\tau-\kappa)-1-\Gamma^{\prime}(\tau)+\lambda_{1}+\lambda_{2}=0 \\
-u^{\prime}(\tau-\kappa)+\delta-\lambda_{1}+\lambda_{3}=0, \\
\lambda_{1}(\kappa-\tau)=0, \lambda_{1} \geq 0, \kappa-\tau \leq 0
\end{gathered}
$$




$$
\begin{aligned}
& \lambda_{2} \tau=0, \lambda_{2} \geq 0, \tau \geq 0, \\
& \lambda_{3} \kappa=0, \lambda_{3} \geq 0, \kappa \geq 0 .
\end{aligned}
$$

i) $\kappa^{*}=\tau^{*}, \tau^{*}=0, \kappa^{*}=0$. Then, $\lambda_{1}+\lambda_{2}=1+\Gamma^{\prime}(0)-u^{\prime}(0)<0$. This is a contradiction.

ii) $\kappa^{*}=\tau^{*}, \tau^{*}>0, \kappa^{*}>0$. Since $\lambda_{3}=0, \lambda_{1}=\delta-u^{\prime}(0)<0$. This is a contradiction.

iii) $\kappa^{*}<\tau^{*}, \tau^{*}>0, \kappa^{*}=0$. Since $\lambda_{1}=\lambda_{2}=0, u^{\prime}\left(\tau^{*}\right)=1+\Gamma^{\prime}\left(\tau^{*}\right)$ and $\lambda_{3}=u^{\prime}\left(\tau^{*}\right)-\delta$.

Because $\lambda_{3} \geq 0$, the condition holds if $u^{\prime}\left(\tau^{*}\right) \geq \delta$. Let $\bar{\delta}=u^{\prime}\left(\tau^{*}\right)$. Then, $\bar{\delta}=1+\Gamma^{\prime}\left(\tau^{*}\right)>1$ because $\tau^{*}>0$. The next case shows that if $\bar{\delta}<\delta, \kappa^{*} \neq 0$ at the optimum.

iv) $\kappa^{*}<\tau^{*}, \tau^{*}>0, \kappa^{*}>0$. Since $\lambda_{1}=\lambda_{2}=\lambda_{3}=0, u^{\prime}\left(\tau^{*}-\kappa^{*}\right)=1+\Gamma^{\prime}\left(\tau^{*}\right)$ and $u^{\prime}\left(\tau^{*}-\kappa^{*}\right)=\delta$. Combining the two, $\Gamma^{\prime}\left(\tau^{*}\right)=\delta-1$. For $\kappa^{*}>0$, it must be $\delta>u^{\prime}\left(\tau^{*}\right)=$ $1+\Gamma^{\prime}\left(\tau^{*}\right)=\bar{\delta}>1$ because $\tau^{*}>0$. There are no other solution candidates.

It is straightforward to check that Berge's theorem of the maximum applies, and thus the solution $\left(\tau^{*}, \kappa^{*}\right)$ is upper hemicontinuous. Since $u^{\prime \prime}(l)<0$ and $\Gamma^{\prime \prime}(\tau)>0$, the solution is single-valued, hence, continuous.

Proof of Proposition 2. (i) Suppose $\delta \leq \bar{\delta}$. Then, $\tau^{*}$ is determined by $u^{\prime}\left(\tau^{*}\right)=1+\Gamma^{\prime}\left(\tau^{*}\right)$ and hence independent of $\delta$. For $\delta>1, \tau^{*}$ is determined by $\Gamma^{\prime}\left(\tau^{*}\right)=\delta-1$. By totally differentiating both sides, $\Gamma^{\prime \prime}\left(\tau^{*}\right) \frac{\partial \tau^{*}}{\partial \delta}=1$. Since $\Gamma^{\prime \prime}>0, \frac{\partial \tau^{*}}{\partial \delta}>0$. Also, $u^{\prime}\left(\tau^{*}-\kappa^{*}\right)=\delta$ holds true, where $u^{\prime \prime}(\tau-\kappa)<0$. By totalling differentiating both sides, $u^{\prime \prime}\left(\tau^{*}-\kappa^{*}\right)\left[\frac{\partial \tau^{*}}{\partial \delta}-\frac{\partial \kappa^{*}}{\partial \delta}\right]=1$. Thus, $\frac{\partial \kappa^{*}}{\partial \delta}=\frac{\partial \tau^{*}}{\partial \delta}-\frac{1}{u^{\prime \prime}}>0$.

(ii) Define $\bar{\delta}_{A}=u^{\prime}\left(\bar{\tau}_{A}\right)=1+\Gamma_{A}^{\prime}\left(\bar{\tau}_{A}\right)$ and $\bar{\delta}_{B}=u^{\prime}\left(\bar{\tau}_{B}\right)=1+\Gamma_{B}^{\prime}\left(\bar{\tau}_{B}\right)$. It can be readily shown that $\bar{\tau}_{A}<\bar{\tau}_{B}$ and $\bar{\delta}_{A}>\bar{\delta}_{B}$. Thus, if $\delta \leq \bar{\delta}_{B}, \tau_{A}^{*}=\bar{\tau}_{A}<\bar{\tau}_{B}=\tau_{B}^{*}$. If $\bar{\delta}_{B}<\delta \leq \bar{\delta}_{A}$, by 2.(i), $\tau_{A}^{*}=\bar{\tau}_{A}<\bar{\tau}_{B}<\tau_{B}^{*}$, and also $\kappa_{A}^{*}=0<\kappa_{B}^{*}$. If $\bar{\delta}_{A}<\delta$, since $1+\Gamma_{A}^{\prime}\left(\tau_{A}^{*}\right)=\delta=1+\Gamma_{B}^{\prime}\left(\tau_{B}^{*}\right), \tau_{A}^{*}<\tau_{B}^{*}$; from $u^{\prime}\left(\tau_{A}^{*}-\kappa_{A}^{*}\right)=\delta=u^{\prime}\left(\tau_{B}^{*}-\kappa_{B}^{*}\right), \kappa_{A}^{*}<\kappa_{B}^{*}$. 
(iii) Define $\bar{\delta}_{A}=u_{A}^{\prime}\left(\bar{\tau}_{A}\right)=1+\Gamma^{\prime}\left(\bar{\tau}_{A}\right)$ and $\bar{\delta}_{B}=u_{B}^{\prime}\left(\bar{\tau}_{B}\right)=1+\Gamma^{\prime}\left(\bar{\tau}_{B}\right)$. It can be readily shown that $\bar{\tau}_{A}>\bar{\tau}_{B}$ and $\bar{\delta}_{A}>\bar{\delta}_{B}$. Thus, if $\delta \leq \bar{\delta}_{B}, \tau_{A}^{*}=\bar{\tau}_{A}>\bar{\tau}_{B}=\tau_{B}^{*}$. If $\bar{\delta}_{B}<\delta<\bar{\delta}_{A}$, by 2.(i), $\tau_{A}^{*}=\bar{\tau}_{A}$ and since $1+\Gamma^{\prime}\left(\tau_{B}^{*}\right)=\delta<\bar{\delta}_{A}=1+\Gamma^{\prime}\left(\bar{\tau}_{A}\right), \bar{\tau}_{A}>\tau_{B}^{*}$. Also, $\kappa_{A}^{*}=0<\kappa_{B}^{*}$. If $\bar{\delta}_{A} \leq \delta, 1+\Gamma^{\prime}\left(\tau_{A}^{*}\right)=\delta=1+\Gamma^{\prime}\left(\tau_{B}^{*}\right)$, thus $\tau_{A}^{*}=\tau_{B}^{*} ;$ from $u_{A}^{\prime}\left(\tau_{A}^{*}-\kappa_{A}^{*}\right)=\delta=u_{B}^{\prime}\left(\tau_{B}^{*}-\kappa_{B}^{*}\right)$, $\kappa_{A}^{*}<\kappa_{B}^{*}$.

Proof of Proposition 3. It is straightforward to show that $\tau_{i}^{*}$ is characterized by $\left(1-\gamma_{i}\right) \delta=$ $1+\Gamma^{\prime}\left(\tau_{i}^{*}\right)$ in the noncooperative equilibrium and by $\delta=1+\Gamma^{\prime}\left(\tau^{h}\right)$ in the cooperative equilibrium.

(i) Since $\gamma_{1}=\gamma_{2}>0$, it follows that $\tau_{1}^{*}=\tau_{2}^{*}=\tau^{*}<\tau^{h}$. Substituting into the first-order conditions, $u^{\prime}\left(\tau^{*}-\kappa_{1}^{*}\right)=\delta=u^{\prime}\left(\tau^{*}-\kappa_{2}^{*}\right)$. Since $u^{\prime}$ is a one-to-one function, $\kappa_{1}^{*}=\kappa_{2}^{*}=\kappa^{*}$. Then, $S W_{1}^{*}=S W_{2}^{*}=u\left(\tau^{*}-\kappa^{*}\right)-\tau^{*}-\Gamma\left(\tau^{*}\right)$. Similarly, it holds that $u^{\prime}\left(\tau^{h}-\kappa_{1}^{h}\right)=\delta=u^{\prime}\left(\tau^{h}-\kappa_{1}^{h}\right)$, so that $\kappa_{1}^{h}=\kappa_{2}^{h}=\kappa^{h}$. Therefore, $\tau^{*}-\kappa^{*}=\tau^{h}-\kappa^{h}$, and $S W_{1}^{h}=S W_{2}^{h}=u\left(\tau^{h}-\kappa^{h}\right)-\tau^{h}-\Gamma\left(\tau^{h}\right) . \Delta S W_{1}=\Delta S W_{2}=\tau^{*}+\Gamma\left(\tau^{*}\right)-\tau^{h}-\Gamma\left(\tau^{h}\right)<0$.

(ii) In the noncooperative equilibrium, since $\gamma_{1}>\gamma_{2}>0$, it follows that $\tau_{1}^{*}<\tau_{2}^{*}<\tau^{h}$. From the first-order conditions, $u^{\prime}\left(\left(1-\gamma_{1}\right) \tau_{1}^{*}-\kappa_{1}^{*}+\gamma_{2} \tau_{2}^{*}\right)=\delta=u^{\prime}\left(\left(1-\gamma_{2}\right) \tau_{2}^{*}-\kappa_{2}^{*}+\gamma_{1} \tau_{1}^{*}\right)$. Since $u^{\prime}$ is a one-to-one function, $\left(1-\gamma_{1}\right) \tau_{1}^{*}-\kappa_{1}^{*}+\gamma_{2} \tau_{2}^{*}=\left(1-\gamma_{2}\right) \tau_{2}^{*}-\kappa_{2}^{*}+\gamma_{1} \tau_{1}^{*}$. Then, $S W_{1}^{*}-S W_{2}^{*}=$ $\tau_{2}^{*}+\Gamma\left(\tau_{2}^{*}\right)-\tau_{1}^{*}-\Gamma\left(\tau_{1}^{*}\right)>0$. In a similar fashion, it can be shown that $S W_{1}^{h}-S W_{2}^{h}=0$. Finally, since $u^{\prime}\left(\left(1-\gamma_{2}\right) \tau^{h}-\kappa_{2}^{h}+\gamma_{1} \tau^{h}\right)=\delta, S W_{2}^{h}-S W_{2}^{*}=\tau_{2}^{*}+\Gamma\left(\tau_{2}^{*}\right)-\tau^{h}-\Gamma\left(\tau^{h}\right)<0$, it follows that $\Delta S W_{1}<\Delta S W_{2}<0$.

Proof of Proposition 4. (i) It is straightforward to show that $\tau_{i}^{*}$ is characterized by $(1-\gamma) \delta=1+\Gamma_{i}^{\prime}\left(\tau_{i}^{*}\right)$ in the noncooperative equilibrium. Since, $\Gamma_{1}^{\prime}(\tau)>\Gamma_{2}^{\prime}(\tau), \tau_{1}^{*}<\tau_{2}^{*}$. It also satisfies $u^{\prime}\left((1-\gamma) \tau_{1}^{*}-\kappa_{1}^{*}+\gamma \tau_{2}^{*}\right)=\delta=u^{\prime}\left((1-\gamma) \tau_{2}^{*}-\kappa_{2}^{*}+\gamma \tau_{1}^{*}\right)$, where $u^{\prime}$ is an injection. 
Thus, $S W_{1}^{*}-S W_{2}^{*}=\tau_{2}^{*}+\Gamma\left(\tau_{2}^{*}\right)-\tau_{1}^{*}-\Gamma\left(\tau_{1}^{*}\right)>0$. On the other hand, in the cooperative case, $\tau^{h}$ is determined by $\delta=1+\Gamma_{1}^{\prime}\left(\tau^{h}\right) / 2+\Gamma_{2}^{\prime}\left(\tau^{h}\right) / 2$. Since $\Gamma_{1}^{\prime}(\tau)>\Gamma_{2}^{\prime}(\tau)$, it can be shown that $\tau^{h}>\tau_{1}^{*}$. It still holds that $u^{\prime}\left((1-\gamma) \tau^{h}-\kappa_{1}^{h}+\gamma \tau^{h}\right)=\delta$. Then, $S W_{1}^{h}-S W_{1}^{*}=\tau_{1}^{*}+\Gamma\left(\tau_{1}^{*}\right)-$ $\tau^{h}-\Gamma\left(\tau^{h}\right)<0$ because $\tau_{1}^{*}<\tau^{h} . \Delta S W_{2}-\Delta S W_{1}=\Gamma_{1}\left(\tau^{h}\right)-\Gamma_{2}\left(\tau^{h}\right)+S W_{1}^{h}-S W_{2}^{*}>0$, where the last inequality holds because $\Gamma_{1}\left(\tau^{h}\right)>\Gamma_{2}\left(\tau^{h}\right)$.

(ii) It is straightforward to show that $\tau_{i}^{*}$ is characterized by $(1-\gamma) \delta=1+\Gamma^{\prime}\left(\tau_{i}^{*}\right)$ in the noncooperative equilibrium, and $\tau^{h}$ is characterized by $\delta=1+\Gamma^{\prime}\left(\tau^{h}\right)$ in the cooperative case. Hence, $\tau_{1}^{*}=\tau_{2}^{*}=\tau^{*}<\tau^{h}$. Using the first-order conditions, $u_{1}^{\prime}\left(\tau^{*}-\kappa_{1}^{*}\right)=\delta=u_{1}^{\prime}\left(\tau^{h}-\kappa_{1}^{h}\right)$ and $u_{2}^{\prime}\left(\tau^{*}-\kappa_{2}^{*}\right)=\delta=u_{2}^{\prime}\left(\tau^{h}-\kappa_{2}^{h}\right)$, where $u^{\prime}$ is an injection. Then, $S W_{1}^{h}-S W_{1}^{*}=\tau_{1}^{*}+\Gamma\left(\tau_{1}^{*}\right)-\tau^{h}-$ $\Gamma\left(\tau^{h}\right)<0$. Also, $\Delta S W_{1}-\Delta S W_{2}=u_{1}\left(\tau^{h}-\kappa_{1}^{h}\right)-u_{1}\left(\tau^{*}-\kappa_{1}^{*}\right)-u_{2}\left(\tau^{h}-\kappa_{2}^{h}\right)+u_{2}\left(\tau^{*}-\kappa_{2}^{*}\right)=0$. 


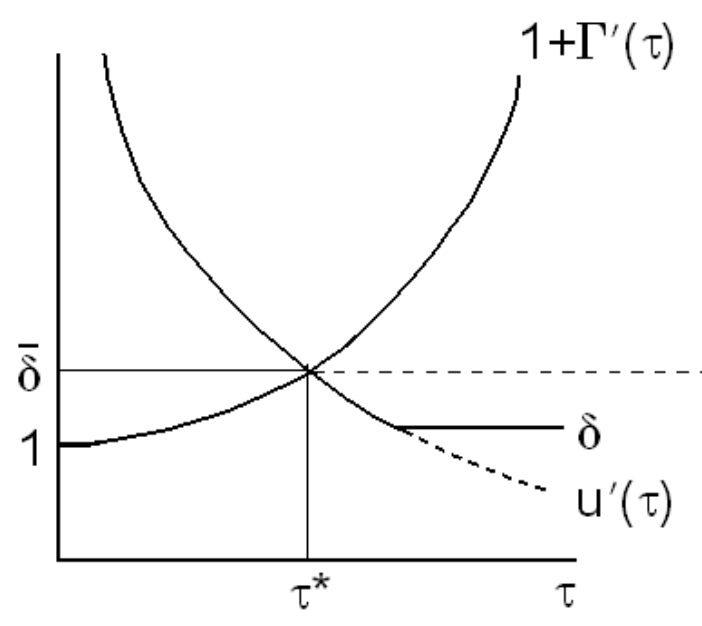

(a) $\delta \leq \bar{\delta}$

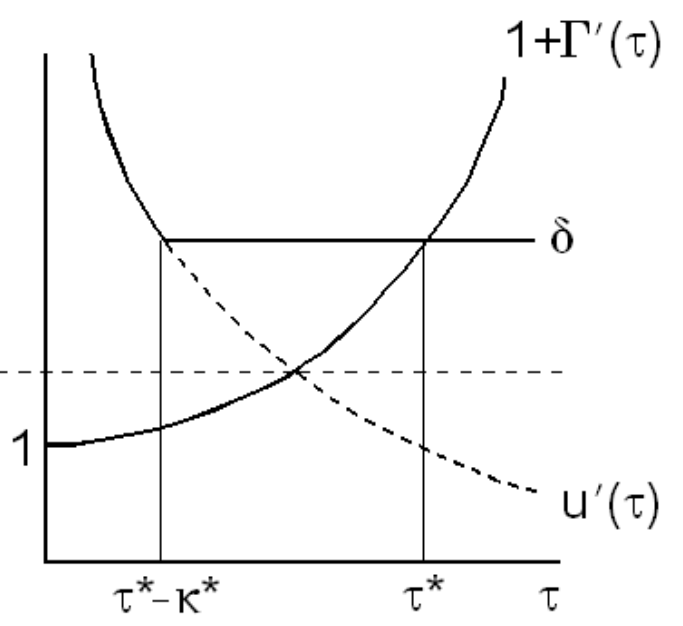

(b) $\delta>\bar{\delta}$

Figure 1: Policymaker's Choice in a Single Country

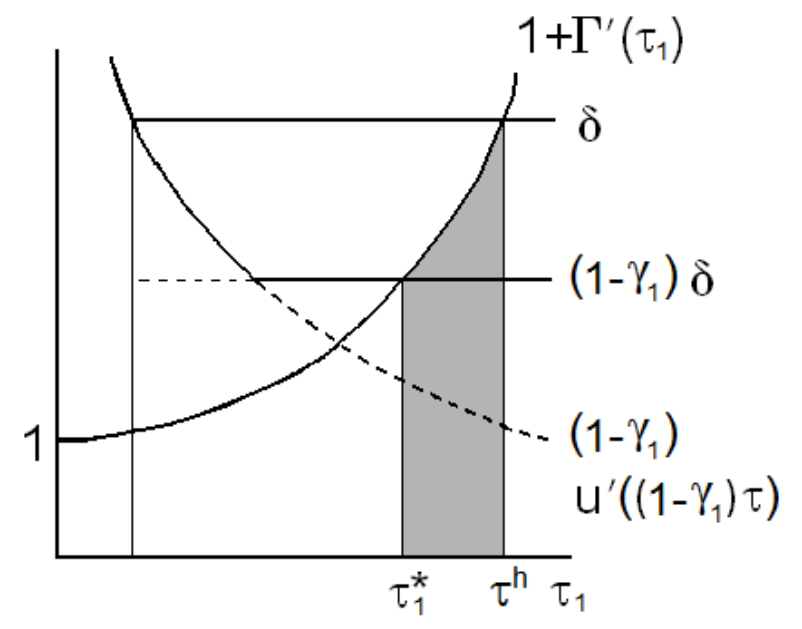

(a) $i=1$

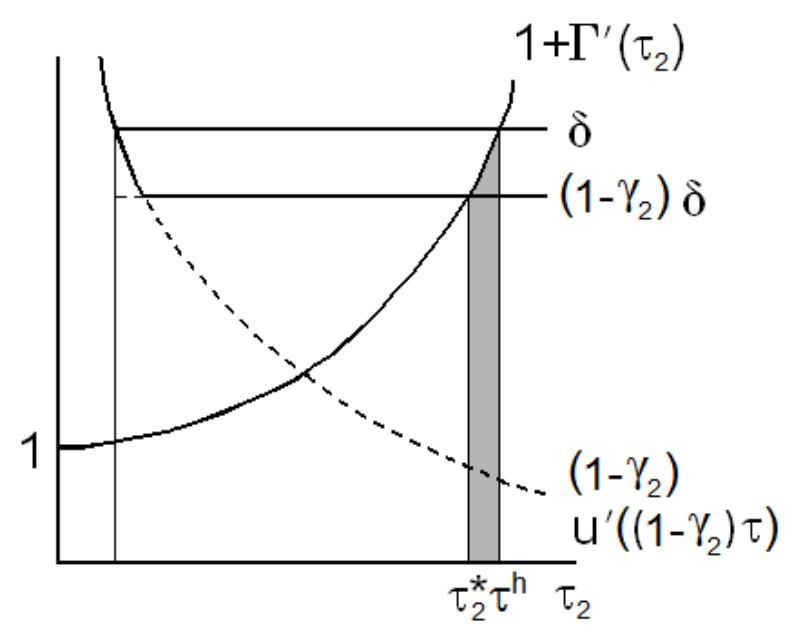

(b) $i=2$

Figure 2: Welfare Losses from Harmonization $\left(\gamma_{1}>\gamma_{2}\right)$ 


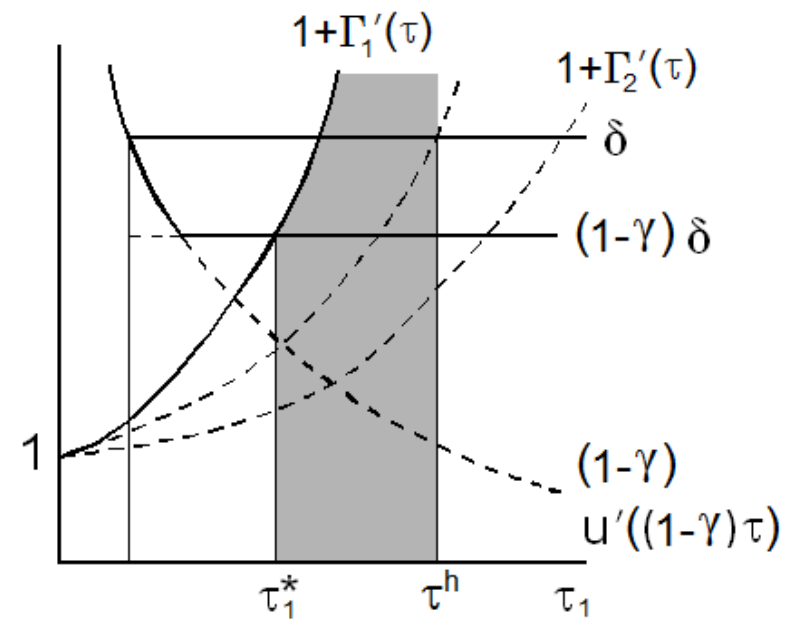

(a) $i=1$

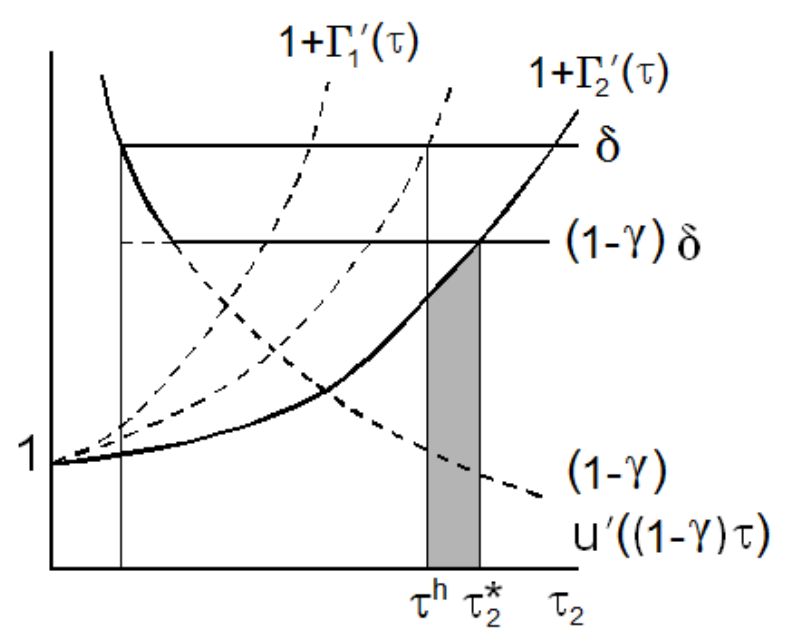

(b) $i=2$

Figure 3: Welfare Loss and Gain from Harmonization $\left(\Gamma_{1}^{\prime}>\Gamma_{2}^{\prime}\right)$

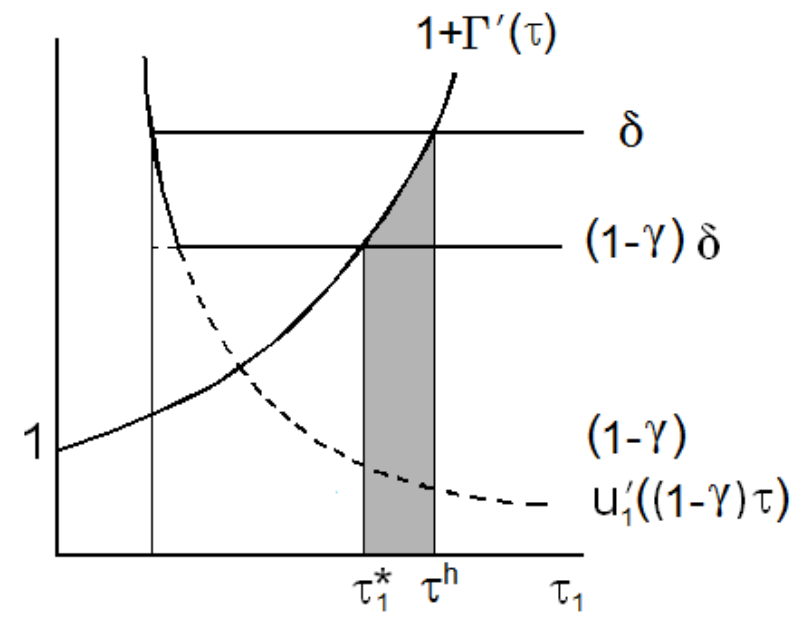

(a) $i=1$

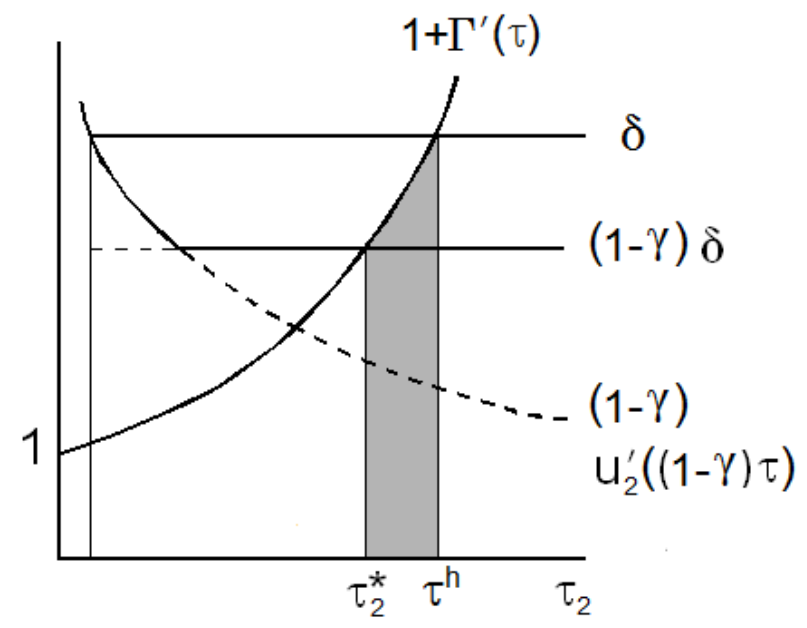

(b) $i=2$

Figure 4: Welfare Losses from Harmonization $\left(u_{1}^{\prime} \neq u_{2}^{\prime}\right)$ 


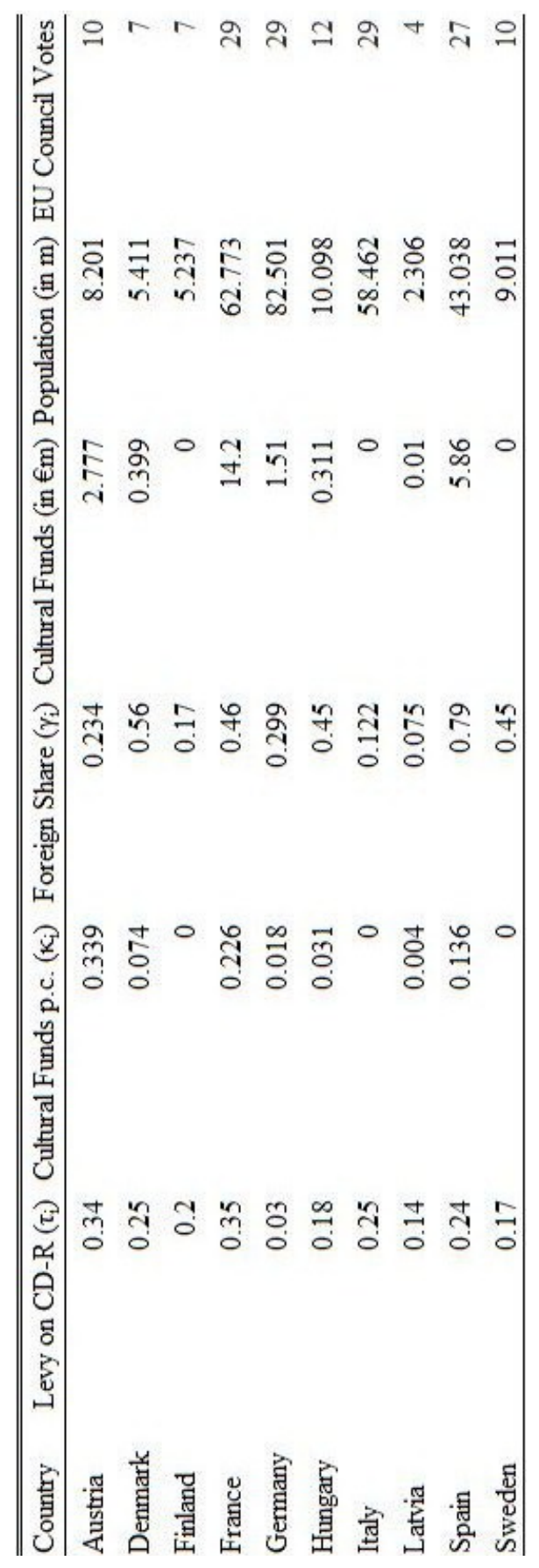

Table. 1: Dataset of 10 European Countries 


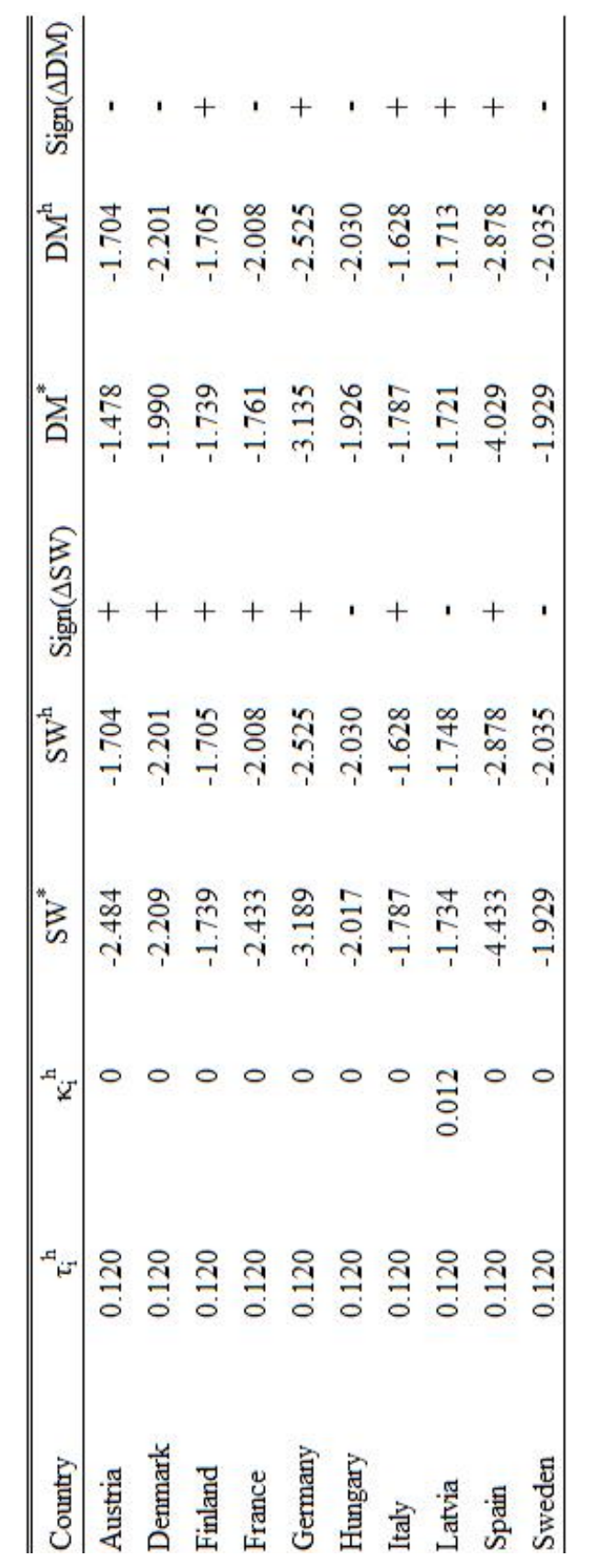

Table. 2: Harmonization with Equal Weight 


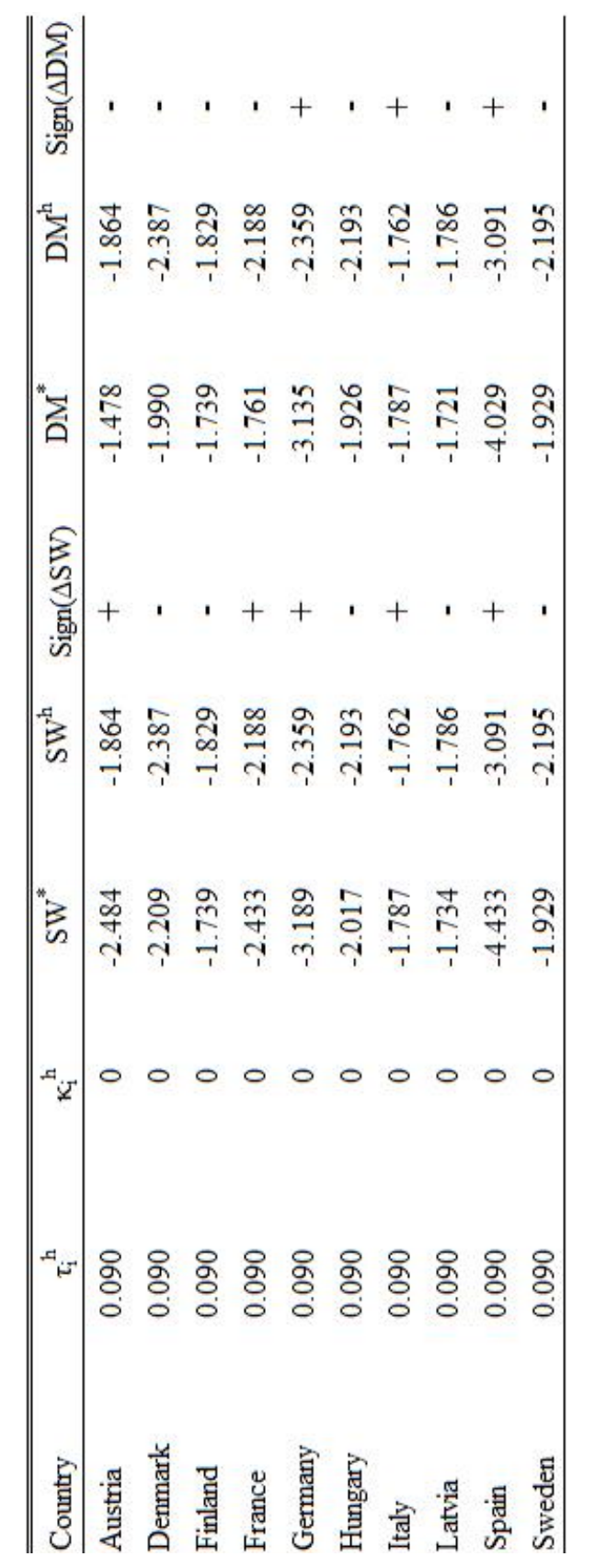

Table. 3: Harmonization with Voting Weight 


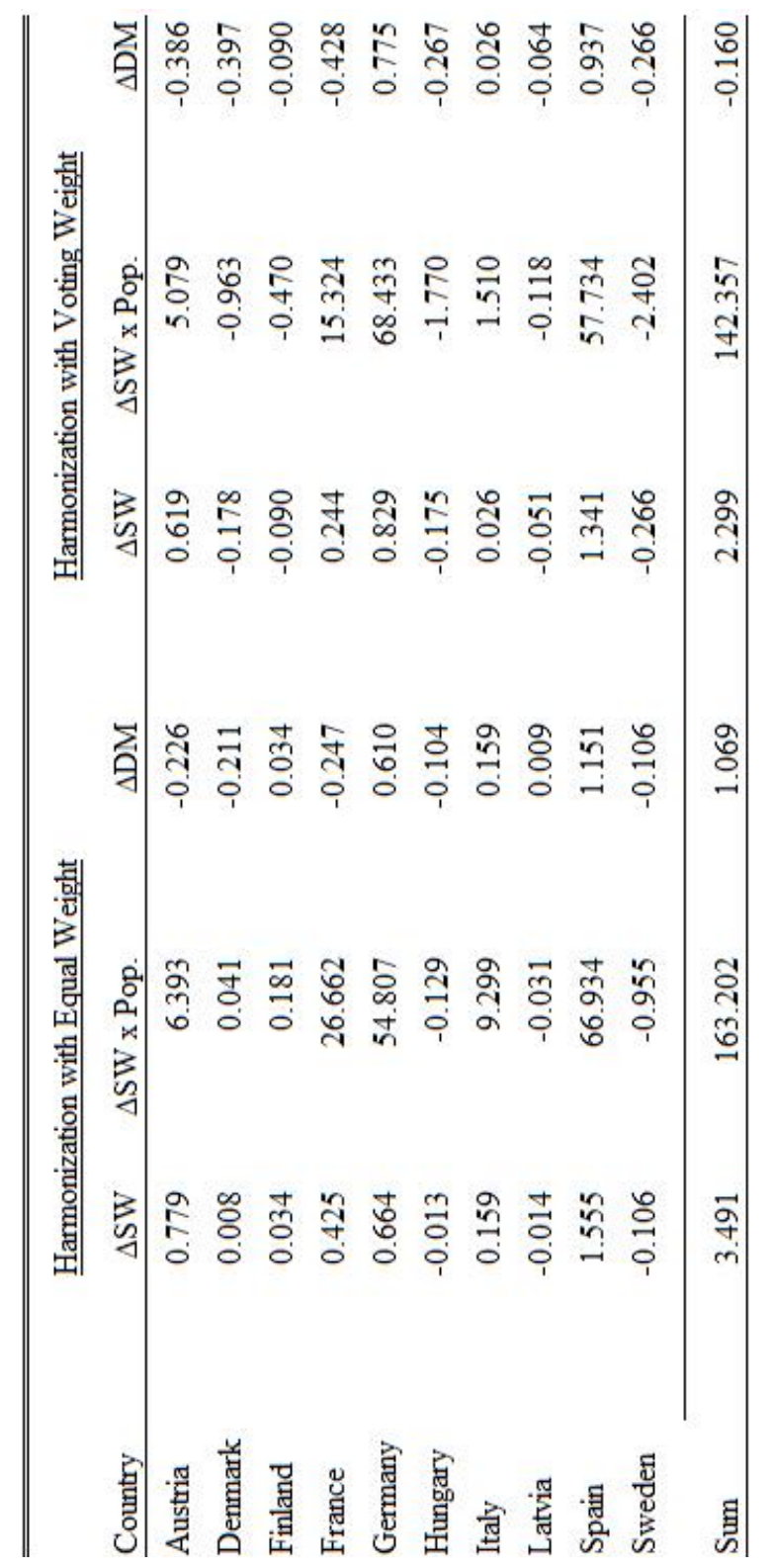

Table. 4: Summary of Welfare Implications 